\title{
Formative qualitative research to develop community-based interventions addressing low birth weight in the plains of Nepal
}

\author{
Joanna Morrison ${ }^{1, *}$, Sophiya Dulal ${ }^{2}$, Helen Harris-Fry ${ }^{1}$, Machhindra Basnet $^{2}$, \\ Neha Sharma ${ }^{2}$, Bhim Shrestha ${ }^{2}$, Dharma Manandhar ${ }^{2}$, Anthony Costello' ${ }^{1}$, David Osrin ${ }^{1}$ \\ and Naomi Saville ${ }^{1}$ \\ ${ }^{1}$ Institute for Global Health, University College London, 30 Guilford Street, London WCIN 1EH, UK: ${ }^{2}$ Mother Infant \\ Research Activities (MIRA), Thapathali, Kathmandu, Nepal
}

Submitted 7 October 2016: Final revision received 27 July 2017: Accepted 16 August 2017: First published online 16 0ctober 2017

\begin{abstract}
Objective: To explore the factors affecting intra-household food allocation practices to inform the development of interventions to prevent low birth weight in rural plains of Nepal.

Design: Qualitative methodology using purposive sampling to explore the barriers and facilitating factors to improved maternal nutrition.

Setting: Rural Dhanusha District, Nepal.

Subjects: We purposively sampled twenty-five young daughters-in-law from marginalised groups living in extended families and conducted semi-structured interviews with them. We also conducted one focus group discussion with men and one with female community health volunteers who were mothers-in-law.

Results: Gender and age hierarchies were important in household decision making. The mother-in-law was responsible for ensuring that a meal was provided to productive household members. The youngest daughter-in-law usually cooked last and ate less than other family members, and showed respect for other family members by cooking only when permitted and deferring to others' choice of food. There were limited opportunities for these women to snack between main meals. Daughters-in-law' movement outside the household was restricted and therefore family members perceived that their nutritional need was less. Poverty affected food choice and families considered cost before nutritional value.

Conclusions: It is important to work with the whole household, particularly mothers-in-law, to improve maternal nutrition. We present five barriers to behaviour change: poverty; lack of knowledge about cheap nutritional food, the value of snacking, and cheap nutritional food that does not require cooking; sharing food; lack of self-confidence; and deference to household guardians. We discuss how we have targeted our interventions to develop knowledge, discuss strategies to overcome barriers, engage mothers-in-law, and build the confidence and social support networks of pregnant women.
\end{abstract}

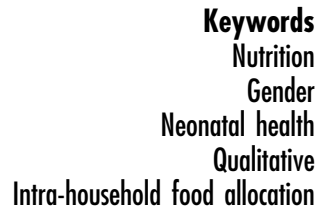

Low birth weight (LBW; <2500 g) affects $15-20 \%$ of babies globally and is a major contributor to neonatal mortality in low-income countries ${ }^{(1)}$. Evidence suggests that LBW babies are also at increased risk of non-communicable diseases later in life ${ }^{(2,3)}$. Preterm birth and in utero growth restriction ${ }^{(4)}$, caused by maternal undernutrition ${ }^{(5)}$, multiple pregnancies ${ }^{(6)}$ and infection ${ }^{(7)}$ can lead to LBW. The WHO has prioritised LBW in its Comprehensive Implementation Plan on Maternal Infant and Young Child Nutrition, leading calls for a $30 \%$ worldwide reduction in prevalence by $2025^{(1)}$. Interventions to encourage behaviour change in communities are necessary for this reduction to occur.
Guidelines for planning and executing complex public health interventions emphasise the importance of formative and theoretical work before conducting randomised controlled trials ${ }^{(8)}$. This is particularly relevant for behaviour change interventions that seek to target specific behaviours $^{(9)}$. Formative research enables interventions to be responsive to contextual barriers and facilitating factors, which may increase their effectiveness ${ }^{(10,11)}$.

We present herein findings from qualitative formative research conducted before the implementation of a complex public health intervention, tested through a four-arm cluster randomised controlled trial, to tackle LBW in the 
rural plains of $\mathrm{Nepal}^{(12)}$. The framework of our interventions was evidence-based and defined before we conducted the formative study, and in the current paper we present how formative research was used to adapt interventions to the local context. Briefly, the interventions were: (i) participatory learning and action (PLA) cycles implemented by women's groups facilitated by female community health volunteers (FCHVs) and nutrition mobilisers (NMs); (ii) PLA cycles combined with $10 \mathrm{~kg}$ of fortified wheat-soya cereal blend with $10 \%$ sugar and an improved micronutrient profile (Super Cereal) to pregnant women in one trial arm; and (iii) PLA cycles combined with monthly cash transfers of 750NRS ( $\sim$ WS 7) to pregnant women in another arm.

Maternal nutrition is an important determinant of LBW and research suggests that Nepalese households discriminate against pregnant women in the allocation of food $^{(13,14)}$. Cultural beliefs, such as jutho (ritual uncleanliness) of pregnant women and beliefs about food properties, have been associated with smaller allocations of food to pregnant women ${ }^{(14)}$. Women also tend to eat fewer high-status 'luxury' foods than men ${ }^{(15)}$, and eating last and being the server has been associated with lower dietary intakes than for other household members ${ }^{(14)}$. Gender role expectations and entitlements limiting women's bargaining power and prioritising the preferences of men and children also affect food allocation $^{(16)}$. Our study explores the factors affecting intra-household food allocation practices in the study district and we describe how our findings were used to inform intervention development.

\section{Methods}

\section{Setting}

The present formative research was conducted in rural Dhanusha District, which is $1180 \mathrm{~km}^{2}$ and has a population of 754777 . Most people are Hindu (90\%) and $88 \%$ speak Maithili, the language of the Maithila ethnic group that predominantly resides in the central and eastern plains areas of Nepal. Nine per cent of the population are from the Muslim community, which is recognised as one of the most marginalised and disadvantaged in Nepal ${ }^{(17)}$. Dhanusha has low levels of literacy: $40 \%$ of women and $61 \%$ of men are literate, and only $14 \%$ of men and $6 \%$ of women have completed their School Leaving Certificate $^{(18)}$. Data from 2011 indicate that $41 \%$ of women were underweight and $17 \%$ had short stature ${ }^{(19)}$. Child undernutrition is high, with $41 \%$ of children stunted and $32 \%$ underweight ${ }^{(20)}$.

\section{Intra-bousebold food study}

We collected data before the start of the trial in four village development committees (VDCs) of Dhanusha District. We purposively sampled marginalised women from poor, extended-family households as we hypothesised that behaviour change would be more difficult in these households. Muslims and Maithili-speaking households are marginalised in this context. Our limited time and resources made it important to focus on these groups. We sampled the youngest daughter-in-law who usually cooked food in the household.

We used surveillance data to locate VDCs with more poor, marginalised households and a local FCHV found women meeting our inclusion criteria. Daughters-in-law can find it difficult to speak freely with other family members present, so we interviewed women in their homes in the afternoon when other family members were unlikely to be present. Interviews explored personal experiences of buying, preparing, cooking and eating food. Eight local, trained female data collectors collected data in Maithili. They had no connection with study participants before the study and had been recruited primarily to supervise and implement the interventions. Participants were illiterate and gave informed verbal consent. Verbal consent was witnessed and formally recorded. Participants were informed that data would be made anonymous.

Initially, we conducted four semi-structured interviews with four daughters-in-law living in poor extended-family households. We adjusted the topic guides and then conducted twenty-one interviews in three VDCs. Sixteen women were from poor households and others were slightly better-off. One woman was not living with her extended family and one woman was not the youngest daughter-in-law. Four women were Muslim and the rest Maithili Hindus of mixed caste. Three interviews were conducted with another family member present, which somewhat affected what participants were able to say. After each interview, we gave the woman a bar of soap. No one refused to participate.

We explored the validity of our interview findings through a focus group discussion with key informants FCHVs who were mostly mothers-in-law from one VDC and a focus group discussion with seven men in another VDC. Discussions took place in community buildings. The men in the focus group discussion were of mixed ethnicity, although all spoke Maithili. Four men were relatives of daughters-in-law we had interviewed, and data collectors approached other male participants in their homes opportunistically and invited them to participate.

Data collectors made field notes, and data were audiorecorded and transcribed by data collectors into Maithili before being translated into English. We did not backtranslate data, as only one researcher could write Maithili and English, and therefore it would not add significant rigour if she were to back-translate the data that she herself had translated. Data collectors added observation notes to the end of each transcript. A group discussion was conducted in Nepali with data collectors to contextualise the data and accurately record the research process. We explored the main findings, their meaning and 
implications, study limitations and any difficulties in data collection. A report of this discussion was written, analysed and used to reflect on the analysis.

Descriptive content analysis was used. J.M. read and made memos on the translated data. A table was made for each transcript and data were copied from transcripts into columns of fifteen descriptive emergent categories. Data from different participants and data sources were compared, consistencies and discrepancies were identified, and linkages were explored. Themes were recurring and triangulated, and given the narrow focus of our research and the homogeneous nature of our sample, we felt that the collection of new data was unlikely to reveal new information. J.M. discussed themes and analysis with S.D. and N.Sh. to consider her role and potential bias, and referred to the discussion with data collectors in interpretation of data. Five main themes were then identified and paper transcripts were coded according to these themes with highlighter pens. Representative quotes, presented below, are identified by type (semi-structured interview (SSI) or focus group discussion (FGD)) and participant number.

\section{Results}

Families usually ate two main meals each day that consisted of rice or bread (roti), lentils (daal), vegetables and pickle (aachar). Poor households usually did not eat breakfast and cooked only one staple food and one type of vegetable per meal. If families ate breakfast, it was usually milk and beaten rice. As this did not require cooking, it saved on fuel and oil.

\section{Housebold structure, family roles and responsibilities}

Most households had a traditional patrilocal structure. After marriage, women moved to their husbands' households that were shared with other sons and their families, unmarried daughters, mother-in-law and father-in-law. In traditional households, family roles were the main factor that affected food purchase, choice, allocation and eating order. Family roles in traditional households tended to be rigid and accepted, with mothers-in-law and their husbands in the role of household guardian until they became too old to do so:

'[My mother-in-law] is my guardian. She should be thinking about these things. I will also have to manage these things in the future when I become the guardian of my family.' (SSI 15)

The mother-in-law was responsible for the moral guardianship and physical safety of her daughters-in-law, and had responsibility for feeding and managing the household, taking money from male earners and allocating tasks. Trust in guardians to provide and protect was implied:

'Whatever the guardian says, will be best.' (SSI 20) and guardians' importance in maintaining household order was respected:

'If the guardian is strict, no one can do this and that, and if the guardian is not strict then the daughter-inlaw makes her guardians harassed.' (Men FGD)

One daughter-in-law told us:

'[My mother-in-law] loves me, as well as beats me.' (SSI 8)

The youngest daughter-in-law usually prepared the food and had the most housework to do:

'[T]he youngest daughter is loaded with work. Everyone orders her to do the work.' (Men FGD)

The daughter-in-law never bought food for the household and relied on others to bring it, apart from one woman living in a nuclear family who went to the market to do her own shopping. It was not culturally acceptable for daughters-in-law living in extended families, particularly younger daughters-in-law, to go outside the household, in poorer or better-off households. A daughterin-law said:

'We don't go outside. We feel shy so we don't go to the market.' (SSI 20)

Daughters-in-law were not usually responsible for money:

'The daughter-in-law has no right to bring in or take money. That is the role of the mother-in-law and husband.' (Men FGD)

The mother-in-law also organised loans when necessary, or asked men to sell produce.

\section{Decision making}

Daughters-in-law could make suggestions about the type of lentils or vegetable to purchase, but this was usually a taste-, quality- or cost-based recommendation rather than a request based on nutritional need or value. Food was bought according to what a family could afford. Men said:

'We purchase food in small quantities, like a kilo at a time. We can only eat the next morning if we earn in the evening.' (FGD)

Lentils were bought in small quantities and if a household was short of money they were not cooked. Because daughters-in-law did not earn and did not handle finances, it was difficult for them to request specific food:

'[The men] bring the food items according to their income. They select the things they can afford, and therefore they decide ... we don't manage anything so how can we decide?' (SSI 15).

Meat and fish were more expensive and were purchased either only when possible or on special occasions. 
Men told us that it was difficult to afford meat for the whole family, and therefore sometimes they ate at a local snack shop, which meant that they did not have to share it with the household.

Fulfilment of a request for a type of staple, lentil or vegetable depended on competing preferences and a daughter-in-law's relationship with her mother-in-law. One daughter-in-law, who was living only with her mother-in-law and children, said that her mother-in-law often brought food that she liked and they had a good relationship. In traditional households, the preferences of the father-in-law and son were prioritised:

'Since my father-in-law doesn't eat that vegetable, I don't cook it.' (SSI 9)

Daughters-in-law tended to cook what they were told to cook, if the food and fuel were available:

'If there are dried leaves and fuel wood at home then I cook whatever they wish. All of them tell me to cook their favourite items, so I have to do so.' (SSI 16)

The mother-in-law usually had the final say over what was cooked. One woman said:

'Everyone wants to eat what they like but I cook whatever my mother-in-law says and everyone eats that.' (SSI 8)

\section{Eating sequence and status}

If it was a traditional household with all the family members present, food was not eaten together as a family. The order of eating was based on status in the home, with the men eating first and then the women, with the youngest daughter-in-law eating last. In traditional Hindu households, the youngest daughter-in-law cooked and served the food, refilling the plate as required, and she could eat only after others had finished eating. Failure to follow these rules was believed to have severe consequences for the family. If the server ate and then touched the food, it was ritually polluted and inedible for other family members. Because of the importance of maintaining purity of the food, the cook must be the server and must eat last. One daughter-in-law said:

'My relatives are more senior than me, I am the youngest. How could I serve my relatives with untouchable [polluted] hands?' (SSI 17)

Status and eating order was usually in accordance with age as well as gender. The few Muslim households that we sampled tended to be larger and the mother-in-law ate a little later, as she read prayers (Namaz). Despite this, and the fact that Muslim households did not follow the traditions of maintaining food purity, the youngest daughter or daughter-in-law still ate last:

'Mother only eats food after reading prayers. I eat food last. I eat food after serving everyone at home.' (SSI 21)
In nuclear households, or households with male migrant workers, decision making about food and traditions around eating were more flexible:

'I bring the vegetables myself. At present, we don't have a guardian in our home [because] they live abroad.' (SSI 18)

Men also concurred:

'The wife will cook according to the guardian ... the families having no guardian cook whatever they like.' (FGD)

Another woman acknowledged that her situation might be different if she did not live in an extended family:

'We could make our own decisions if we lived separately. We depend on my husband's parents at the moment.' (SSI 7)

\section{Productive work}

Food allocation was also linked to economic contributions. Those who worked outside the home earning money usually had first choice about what was cooked. They ate first and ate until they were full:

'They will only earn and bring the money if they have fulfilled their appetite. They will only be able to work if they eat properly ... they do construction work, so they don't eat bread. They say that they don't get so much strength to work when they eat bread.' (SSI 19)

Work outside the home was perceived to be more strenuous than work inside the home and therefore it was justifiable that younger daughters-in-law, staying inside the household, should eat less:

'My sisters-in-law do lots of work within the home as well as outside the home, so I give them more food. They bring grasses, husks and firewood. I only cook food.' (SSI 4)

When we asked men why family members ate more or less, they said:

'It is because of their work ... some do more work, while some do less work. The person who does not do any work eats less ... will the person who just sits at home without doing any work be minded to eat more?' (FGD)

Men told us:

'Women have leisure time. Men don't have leisure time. They do outdoor work, farming or doing service. Whoever has leisure time will cook the food.' (FGD)

There was also a belief that those who stayed at home had the opportunity to eat more because they could snack more:

'Those who stay at home eat more. Because daughters-in-law are at home, they eat more ... it is 
very obvious that they would eat more than men.' (FCHV FGD)

Data collectors observed little or no snack food kept in the houses of poor families, and it usually required cooking. The perception of daughters-in-law eating the family food might help to explain the tight control of mothers-in-law over daughters-in law. Daughters-in-law could cook and eat only after obtaining permission and eating without permission was viewed very negatively. Men told us:

'If she doesn't eat in front of her mother-in-law, then that is stealing food.' (FGD)

Children tended to be less affected by status and routine and tended to eat when they were hungry. It was also reported that household guardians gave preference to children when any special food in the household was distributed.

\section{Respect}

Daughters-in-law were often shocked at the suggestion that the eating order could be different:

'How can we eat all together? We don't eat together.' (SSI 10)

They were worried about what people would say, how their guardians would feel, and felt that it was very disrespectful:

'They are above me, so how can I eat earlier than them?' (SSI 19)

One woman told us:

'We respect our father by serving him in the very beginning. He is only respected by us if he eats first.' (SSI 14)

Another woman said:

'We eat last every day. How can we eat if our guardians are at home? It isn't good if we eat first if they are still at home. That is not a good habit.' (SSI 15)

Men and FCHVs also reported and did not question this custom. Men said:

'This is what happens in the Maithili culture. The women don't eat if their husbands have not eaten even if morning changed into night. How can they eat earlier than their husbands if their husbands haven't eaten yet? ... [T]his is the custom that is practised ... [the daughter-in-law] is obeying her responsibilities.' (Men FGD)

There was also evidence that daughters-in-law felt uncomfortable eating with older family members:

'As she is the new member of the family she feels very shy to eat and therefore she eats less.' (Men FGD)
A few daughters-in-law said that they were only comfortable if they had served others first:

'I only eat after feeding everyone at home. I am relaxed after they have eaten.' (SSI 6)

Daughters-in-law and FCHVs found it difficult to discuss the amount of food eaten by family members because it would be disrespectful to say that someone ate more than someone else. In addition, meals are a time when individuals were vulnerable to witchcraft. Data collectors told us that jealous family members could curse food by looking at it. Disrespect and fear of demonstrating jealousy helped explain participants' reluctance to discuss quantities of food eaten by household members:

'Oh my god! How will I know who eats more? How can I say these things about who eats more and who eats less? I can't tell you the name of who eats more and who eats less!' (SSI 8)

Another woman told us:

'There is a proverb in Maithili - nobody knows about one's stomach and one's land. My family members eat as much as they like. I won't say who eats more in my house.' (SSI 15)

Many daughters-in-law told us that they themselves ate the most in the household - perhaps to show respect to other members - and yet told us that sometimes there wasn't enough food left for them to eat.

Daughters-in-law said that sometimes the food they cooked ran out before they had eaten:

'I eat last so I don't get enough food sometimes.' (SSI 8)

Some said that they cooked again, especially if there were other family members who had also not eaten. One woman said:

'I cook food again. I do whatever my mother-in-law tells me to do.' (SSI 22)

Others said that they prepared chilli and salt with bread or beaten rice:

'I am the youngest daughter-in-law so I eat last. I eat whatever is left after feeding everyone. I eat rice if there is some left, and if not then I don't eat. I eat pickle.' (SSI 5)

Some told us that vegetables tended to run out:

'Fewer vegetables are cooked when they are expensive and therefore there isn't always enough.' (SSI 6)

Women ensured that men and children were able to eat vegetables and they sometimes went without. Men said:

'Women serve us more vegetables in the meal and therefore they eat less vegetables, as the 
vegetables are cooked in limited amounts' (FGD)

Another woman said:

'I am never certain that there will be vegetables left for me to eat. I keep vegetables for my children as they will cry if there aren't any vegetables for them. We have to satisfy ourselves by eating what is there.' (SSI 1)

Some participants were reluctant to say that they went hungry and said that they ate as much as they wanted:

'Whether I eat or not, it doesn't matter.' (SSI 19)

\section{Discussion}

We have shown that the role of gender and age in intrahousehold food allocation is likely to be important in understanding the causes of LBW and in developing interventions to improve maternal nutrition. Our analysis suggests that poverty and hierarchical structures within households prevent equitable allocation of food, negatively affecting younger daughters-in-law. Study participants told us that younger daughters-in-law in traditional households usually eat last, eat less and have almost no control over what food is cooked, consistent with findings from other studies ${ }^{(13,14)}$.

\section{Engaging bierarchies}

Intergenerational and gender-based hierarchical household structures observed in the present study have been associated with harmful effects on children's health and nutrition $^{(21-24)}$. To promote a fairer allocation of food in hierarchical extended-family households, it is important to work with higher-status family members, such as mothersin-law. There is some evidence to suggest that engaging these household members in interventions could be effective in improving household nutrition ${ }^{(25)}$.

For religious and cultural reasons, the youngest daughter-in-law cooks and serves the meals ${ }^{(26)}$. She also demonstrates her respect to older family members and household guardians by accepting her position and cooking only with permission of her mother-in-law ${ }^{(27)}$. Studies have shown that this has a negative effect on a woman's nutritional status ${ }^{(14,28)}$. Our study also suggests that this practice results in daughters-in-law eating fewer vegetables and less food, despite elevated nutritional needs during pregnancy ${ }^{(29)}$.

The impact of eating less and eating last should be considered in context. Participants in our study perceived that younger daughters-in-law' restriction to the home meant that their nutritional need was less, but there is little evidence to support this conclusion. In fact, studies suggest that the energy adequacy of women may be overestimated because their energy expenditure is underestimated $^{(30)}$ and assumptions about increased nutritional needs of men due to high energy expenditure through strenuous physical work have been challenged by research in a remote hill area of $\mathrm{Nepal}^{(31)}$. Further research is required to understand the nutritional need and energy expenditure of men and women in poor households in the plains of Nepal.

Younger daughters-in-law in our study had little opportunity to eat outside the household as they were not allowed to go outside and had restricted access to cash. Although there was a perception that daughters-in-law snacked more because they were at home all day, data collectors were sceptical that this was an accurate representation of the situation in households they visited.

\section{Study implications}

The formative data from the present study allowed us to adapt the interventions to the local context and specify the main barriers that communities would have to overcome for women to achieve better maternal nutrition. Our formative findings support holistic approaches to improving women's status and facilitating change at the household and community level. In Fig. 1 we present the five main barriers to behaviour change in this context and demonstrate the ways in which our interventions address them.

Interventions will build knowledge about the causes and consequences of LBW and offer practical strategies for families to address poor maternal nutrition. For example, the women's groups will discuss cheap, seasonal vegetables with high nutritional value and appropriate snack foods that do not require cooking. Women's groups, FCHVs and NMs will also discuss strategies for making incremental changes to intra-household norms while a woman is pregnant; for example, another daughter-in-law cooking for the duration of the pregnancy, or a pregnant daughter-in-law serving food for herself at the same time as others (but not necessarily eating the food) to ensure she has an adequate amount. The positive, supportive role of the mother-in-law will be emphasised ${ }^{(32)}$ in protecting the unborn child. She will be invited to women's group meetings and encouraged to give permission to the daughter-in-law to snack, go to women's group meetings, not share her Super Cereal and ensure her adequate access to food. Women's groups, FCHVs and NMs will also discuss optimal spending of the cash transfer with the family as a whole, so the daughter-in-law can ask others to buy her food, or she can access appropriate food that is nearby.

We will develop the social support networks of daughters-in-law at women's group meetings and help develop their confidence to advocate for their nutritional needs through participating in community action ${ }^{(33,34)}$. In addition, we will encourage FCHVs and NMs to reinforce the need for behaviour change and create social pressure to conform to norms that recognise the nutritional needs of pregnant women. 


\begin{tabular}{|c|c|c|}
\hline Barriers & Interventions \& stakeholders & Effect \\
\hline Lack of self-confidence & $\begin{array}{l}\text { Behaviour change strategy } \\
\text { (BCS) with daughters-in-law }\end{array}$ & $\begin{array}{l}\text { - Increased social networks } \\
\text { - Increased confidence to advocate for needs }\end{array}$ \\
\hline $\begin{array}{l}\text { - Daughter-in-law's lack of } \\
\text { agency } \\
\text { - Respect linked to food } \\
\text { behaviours }\end{array}$ & BCS with mothers-in-law & $\begin{array}{l}\text { - Emphasise caretaking role of mother-in-law in } \\
\text { protecting unborn child through good maternal } \\
\text { nutrition } \\
\text { - Permission for daughter-in-law to cook, snack, go } \\
\text { to meetings, spend money on herself }\end{array}$ \\
\hline Poverty & $\begin{array}{l}\text { BCS with all family members }+ \\
\text { cash transfers }+ \text { Super Cereal }\end{array}$ & $\begin{array}{l}\text { - Improved access to food } \\
\text { - More effective spending on seasonal nutritious } \\
\text { foods, and healthy snacks not requiring cooking }\end{array}$ \\
\hline Sharing of food & $\begin{array}{l}\text { BCS with all family members }+ \\
\text { additional Super Cereal }\end{array}$ & $\begin{array}{l}\text { - Enable sharing of Super Cereal } \\
\text { - Decrease acceptability of sharing Super Cereal }\end{array}$ \\
\hline $\begin{array}{l}\text { Lack of knowledge about: } \\
\text { - Cheap locally available } \\
\text { foods } \\
\text { - Nutritional needs and } \\
\text { consequences of poor } \\
\text { maternal nutrition } \\
\text { - Nutritious snack foods that } \\
\text { do not require cooking } \\
\text { - How to cook Super Cereal }\end{array}$ & BCS with all family members & $\begin{array}{l}\text { - Informed self-advocacy } \\
\text { - Informed advocacy from other household } \\
\text { members } \\
\text { - Decrease acceptability of eating less } \\
\text { - Effective use of cash transfer } \\
\text { - Non-pregnant daughter-in-law cooking and } \\
\text { serving food }\end{array}$ \\
\hline
\end{tabular}

Fig. 1 Barriers to behaviour change and interventions to address them

\section{Limitations}

Ethnographic methods or a longitudinal approach might have enabled a deeper understanding of intra-household issues. It was sometimes difficult to talk to women in private, decreasing the ability of participants to communicate about perceived subversive activity. Nevertheless, the shock demonstrated by daughters-in-law when we suggested changing eating order, and triangulation of findings in discussions with men and FCHVs, gives us confidence in our findings. There was little difference between Muslim and Hindu households, but our small sample of Muslim women limits the strength of our conclusions. There were indications that there was more flexibility in food allocation in migrant worker or nuclear family households, but we were unable to explore this in our study.

\section{Conclusion}

We have presented a detailed description of intrahousehold food allocation practices in poor households in the rural plains of Nepal. It was important to develop an explicit and detailed understanding about how food was usually acquired and managed in households, to develop a culturally sensitive, targeted intervention. Our intervention will focus on households and communities instead of individuals, with particular focus on mothers-inlaw. To enable better maternal nutrition, we need to equip households with knowledge and resources, and promote community dialogue, to develop an enabling household and community context where families can change their behaviour and the incidence of LBW is reduced.

\section{Acknowledgements}

Acknowledgements: The authors would like to thank the study participants, members of the Low Birth Weight Trial South Asia Study Team and Trial Steering Committee members. They would also like to thank the District Health Offices of Dhanusha and Mahottari for their support. Financial support: This research was supported by the UK Department for International Development (grant number PO5675) and the Wellcome Trust (grant number 085417/ Z/08/Z). The UK Department for International Development and the Wellcome Trust had no role in the design, analysis or writing of this article. Conflict of interest: None. Authorship: J.M. conceived of and designed the study, analysed the data and wrote the first draft of the manuscript. S.D., H.H.-F., M.B. and N.Sh. participated in data analysis and interpretation, and in addition N.Sh. transcribed and translated data. B.S., D.M., A.C., D.O. and N.Sa. provided managerial support to the study. All authors read and commented on drafts of the manuscript. Etbics of buman subject participation: This study was conducted according to the guidelines laid down in the Declaration of Helsinki and all procedures involving human subjects/patients were approved by the Nepal Health Research Council (108/2012) and University College London Ethical Review Committee (4198/001). 


\section{References}

1. World Health Organization (2014) Global Nutrition Targets 2025: Low Birth Weight Policy Brief. http://www.who.int/ nutrition/publications/globaltargets2025_policybrief_lbw/en/ (accessed September 2017).

2. Victora C, Adair L, Fall C et al. (2008) Maternal and child undernutrition: consequences for adult health and human capital. Lancet 371, 340-357.

3. Martorell R \& Zongrone A (2012) Intergenerational influences on child growth and undernutrition. Paediatr Perinat Epidemiol 26, Suppl. 1, 302-314.

4. Villar J \& Belizan J (1982) The relative contribution of prematurity and fetal growth retardation to low birthweight in developing and developed societies. Am J Obstet Gynecol 143, 793-798.

5. Kramer M (1987) Determinants of low birth weight: methodological assessment and meta-analysis. Bull World Health Organ 65, 663-737.

6. Conde-Agudelo A, Rosas-Bermudez A \& Kafury-Goeta A (2006) Birth spacing and risk of adverse perinatal outcomes: a meta-analysis. JAMA 295, 1809-1723.

7. Guyatt H \& Snow R (2004) Impact of malaria during pregnancy on low birthweight in Sub-Saharan Africa. Clin Microbiol Rev 17, 760-769.

8. Craig P, Dieppe P, Macintyre S et al. (2013) Developing and evaluating complex interventions: the new Medical Research Council guidance. Int J Nurs Stud 20, 585-592.

9. Michie S \& Prestwich A (2010) Are interventions theory based? Development of an intervention theory coding scheme. Health Psychol 29, 1-8.

10. Neonatal Mortality Formative Research Working Group (2008) Developing community-based intervention strategies to save newborn lives: lessons learned from formative research in five countries. J Perinatol 28, Suppl. 2, S2-S8.

11. Panter-Brick C, Clarke S, Lomas H et al. (2006) Culturally compelling strategies for behaviour change: a social ecology model and case study in malaria preventions. Soc Sci Med 62, 2810-2825.

12. Saville N, Shrestha B, Style S et al. (2016) Protocol of the Low Birth Weight South Asia Trial (LBWSAT), a cluster randomised controlled trial testing the impact of birth weight and infant nutrition of participatory learning and action through women's groups, with and without conditional transfers for fortified food or cash during pregnancy in Nepal. BMC Pregnancy Childbirth 16, 320.

13. Harris-Fry H (2016) Intra-household Food Allocation in Rural Nepal. London: University College London.

14. Gittelsohn J (1991) Opening the box: intrahousehold food allocation in rural Nepal. Soc Sci Med 33, 1141-1153.

15. Sudo N, Sekiyama M, Ohtsuka R et al. (2009) Gender differences in 'luxury food intake' owing to temporal distribution of eating occasions among adults of Hindu communities in lowland Nepal. Asia Pac J Clin Nutr 18, 441-446.

16. Daivadanam M, Wahlstrom R, Thankappan KR et al. (2015) Balancing expectations amidst limitations: the dynamics of food decision-making in rural Kerala. BMC Public Health 15, 664
17. Constitution Drafting Committee (2072) Constitution of Nepal (unofficial translation). Kathmandu: Constituent Assembly Secretariat.

18. Central Bureau of Statistics (2012) National Population and Housing Census 2011. Kathmandu: National Planning Commission, Central Bureau of Statistics, Government of Nepal.

19. Shrestha B, Bhandari B, Manandhar D et al. (2011) Community interventions to reduce child mortality in Nepal: MIRA Dhanusha cluster randomized controlled trial. Trials 12, 136.

20. Ministry of Health and Population (2011) Nepal Demographic and Health Survey. Kathmandu: Population Division, Ministry of Health and Population, Government of Nepal, New Era and ICF International.

21. Doan R \& Bisharat L (1990) Female autonomy and child nutritional status: the extended family residential unit in Amman, Jordan. Soc Sci Med 31, 783-789.

22. Castle SE (1993) The (re)negotiation of illness diagnosis and responsibility for child death in rural Mali. Med Anthropol $Q$ 8, 314-335.

23. Dancer D \& Rammohan A (2009) Maternal autonomy and child nutrition: evidence from rural Nepal. Indian Growth Dev Rev 2, 18-38.

24. Hossain MB, Philips JF \& Pence B (2008) The effect of women's status on infant and child mortality in four rural areas of Bangladesh. J Biosoc Sci 39, 355-366.

25. Aubel J, Toure I \& Diagne M (2004) Senegalese grandmothers promote improved maternal and child nutrition practices: the guardians of tradition are not averse to change. Soc Sci Med 59, 945-959.

26. Bennett L (1997) Dangerous Wives and Sacred Sisters. Kathmandu: Mandala Book Point.

27. Messer E (1997) Intra-household allocation of food and health care: current findings and understandings - introduction. Soc Sci Med 44, 1675-1684.

28. Khan M, Anker R, Dastidar S et al. (1987) Inequalities Between Men and Women in Nutrition and Family Welfare Services: An In-depth Enquiry in an Indian Village. Geneva: World Employment Programme Research, UNFPA Project No. INT/83/P34.

29. Indian Council of Medical Research (2010) Nutrient Requirements and Recommended Dietary Allowances for Indians. Hyderabad: National Institute of Nutrition, ICMR.

30. DeRose LF, Das M \& Millman SR (2000) Does female disadvantage mean lower access to food? Popul Dev Rev 26, 517-547.

31. Panter-Brick C (1996) Seasonal and sex variation in physical activity levels among agro-pastoralists in Nepal. Am J Phys Anthropol 100, 7-21.

32. Aubel J (2010) The Roles and Influence of Grandmothers and Men. Washington, DC: US Agency for International Development.

33. Morrison J, Thapa R, Hartley S et al. (2010) Understanding how women's groups improve maternal and newborn health in Makwanpur, Nepal: a qualitative study. Int Health 2, 25-35.

34. Rath S, Nair N, Tripathy P et al. (2010) Explaining the impact of a women's group led community mobilisation intervention on maternal and newborn health outcomes: the Ekjut trial process evaluation. BMC Int Health Hum Rights 10, 25. 